\title{
Patient-Ventilator Interactions: Optimizing Conventional Ventilation Modes
}

\author{
Neil R MacIntyre MD FAARC
}

\author{
Introduction \\ Features Available on Conventional Modes That Enhance Synchrony \\ Breath and Mode Design Features \\ Monitoring Techniques for Synchrony \\ Using These Conventional Features at the Bedside to Improve Patient- \\ Ventilator Interaction \\ Optimizing Breath Triggering \\ Optimizing Flow Delivery \\ Optimizing Breath Cycling \\ The Distribution of Ventilator Breaths May Affect Synchrony \\ Summary
}

\begin{abstract}
Assisted (interactive) breathing is generally preferred to controlled breaths in patients on mechanical ventilators. Assisted breaths allow the patient's respiratory muscles to be used, and ventilatory muscle atrophy can be prevented. Moreover, the respiratory drive of the patient does not have to be aggressively blunted. However, interactive breaths need to be synchronized with the patient's efforts during the trigger, the flow delivery, and the cycling phases. Asynchrony during any of these can put an intolerable load on the respiratory muscles, leading to fatigue and the need for a high level of sedation or even paralysis. Current ventilation modes have a number of features that can monitor and enhance synchrony, including adjustment of the trigger variable, the use of pressuretargeted versus fixed-flow-targeted breaths, and manipulations of the cycle variable. Clinicians need to know how to use these ventilation mode and monitor them properly, especially understanding the airway pressure and flow graphics. The clinical challenge is synchronizing ventilator gas delivery with patient effort. Key words: mechanical ventilation; patient-ventilator synchrony; ventilation modes. [Respir Care 2011;56(1):73-81. (C) 2011 Daedalus Enterprises]
\end{abstract}

\section{Introduction}

Breaths delivered by a mechanical ventilator can be considered as either controlled or assisted. ${ }^{1}$ A controlled breath

\footnotetext{
Neil R MacIntyre MD FAARC is affiliated with the Division of Pulmonary and Critical Care Medicine, Duke University Medical Center, Durham, North Carolina.

Dr MacIntyre presented a version of this paper at the 46th RESPIRATORY CARE Journal Conference, "Patient-Ventilator Interaction," held March 1921, 2010, in Cancún, Quintana Roo, Mexico.
}

means that the machine determines the rate, the inspiratory time, and the tidal volume $\left(\mathrm{V}_{\mathrm{T}}\right)$, so the patient does no work. With controlled breaths, sedation and paralysis may be needed to suppress patient activity that might interfere with breath

Dr MacIntyre has disclosed a relationship with CareFusion.

Correspondence: Neil R MacIntyre MD FAARC, Division of Pulmonary and Critical Care Medicine, Duke University Hospital, Box 3911, Durham NC 27710. E-mail: neil.macintyre@duke.edu. 
Table 1. Trigger, Target, and Cycle Criteria of the 5 Basic Breath Types

\begin{tabular}{llll}
\hline \hline \multicolumn{1}{c}{ Breath Type } & Trigger & Target & Cycle \\
\hline Volume control & Timer & Flow & Volume \\
Volume assist & Effort & Flow & Volume \\
Pressure control & Timer & Pressure & Time \\
Pressure assist & Effort & Pressure & Time \\
Pressure support & Effort & Pressure & Flow \\
\hline
\end{tabular}

delivery. There is also a risk of diaphragmatic muscle structural derangement and atrophy (ventilator-induced diaphragmatic dysfunction). ${ }^{2,3}$ In contrast, in an assisted breath the patient interacts in some way with the ventilator, so the work of breathing is shared between the ventilator and the patient. ${ }^{4-7}$ The level of patient work is minimal if all the patient does is trigger the breath, or the patient work can be considerable if the ventilator's flow delivery and/or pressure application is minimal.

With assisted breaths, sedation needs may be less and patient muscle function may recover more rapidly, $, 5,6$ but this requires that the ventilator's flow and pressure delivery are synchronized with the patient's effort during all 3 breath phases: initiation, delivery, and termination. Triggering delays, inadequate flow delivery, or mismatching of the end of inspiration and the beginning of expiration can place a considerable load on the patient ${ }^{5-7}$ and lead to muscle fatigue, discomfort, and an increasing need for sedation or even paralytics. The importance of patient-ventilator asynchrony has been shown in several studies. ${ }^{8-11}$ In one, substantial asynchrony was associated with much longer duration of mechanical ventilation and even a trend toward a worse mortality. ${ }^{8}$ The clinical challenge, then, is to provide ventilatory support that is in accordance with patient effort: this is the concept of synchronizing mechanical ventilation to the patient's respiratory drive.

\section{Features Available on Conventional Modes That Enhance Synchrony}

\section{Breath and Mode Design Features}

As noted above, ventilator breaths can be described by what initiates the breath, what governs gas flow during the breath, and what terminates the breath (the trigger, target, and cycle variables, respectively). Conventional ventilators today deliver 5 basic breath types (Table 1 and Fig. 1):

- The volume-control breath is time-triggered, flow-targeted, and volume-cycled.

- The volume-assist breath is effort-triggered, flow-targeted, and volume-cycled.
- The pressure-control breath is time-triggered, pressuretargeted, and time-cycled.

- The pressure-assist breath is effort-triggered, pressuretargeted, and time-cycled.

- The pressure-support breath is effort-triggered, pressuretargeted, and flow-cycled.

Three of these breath types can be considered assisted or interactive breaths: volume-assist, pressure-assist, and pressure-support.

The mechanical ventilation modes are the ways in which these 5 basic breaths can be delivered to the patient (Table 2). The volume assist-control mode provides volumecontrol and volume-assisted breaths. If the machine breath rate is set very high, the mode becomes virtually only volume control; in contrast, if the mandatory breath rate is set very low and patient triggers most of these breaths, the mode essentially becomes a pure volume-assist mode. Similarly, the pressure assist-control mode has a combination of pressure-control and pressure-assisted breaths. Again, depending upon the set machine rate, the breaths can be predominantly pressure-control or predominantly pressureassist. Synchronized intermittent mandatory ventilation (SIMV) modes mix either (1) volume-assist and volumecontrol breaths with pressure-support or spontaneous breaths, or (2) pressure-assist and pressure-control breaths interspersed with pressure-support and/or spontaneous breaths. Finally, pressure-support ventilation (PSV) can be a stand-alone mode in which only pressure-support breaths are given. As a side note, the novel mode airway pressure release ventilation (APRV) is really a form of SIMV in that APRV provides essentially a pressure-assist-control breath with a very long inspiratory time and allows spontaneous breathing during both the inflation and deflation phase.

In applying these conventional ventilation modes, several design features can be used to improve patient-ventilator synchrony. For breath triggering the clinician can choose either a pressure trigger or a flow trigger, and can set the trigger as sensitive as possible. When breath triggering is impeded by intrinsic PEEP, the clinician can also add extrinsic or circuit PEEP to overcome that impedance. During flow delivery the clinician can choose either flow or pressure targeting. With flow targeting the flow is fixed. With pressure targeting the flow will adjust to maintain a target pressure. Pressure-targeted breaths also have additional features that control the rate of pressure rise, and algorithms that can adjust the pressure target to compensate for the endotracheal tube. For breath cycling, the clinician can set the volume (in volume-control and volumeassist breaths), the inspiratory time (in pressure-control and pressure-assist breaths), or the inspiratory flow cutoff (in pressure-support breaths) to optimize synchrony. Fi- 
Volume Control Volume Assist Pressure Control Pressure Assist Pressure Support
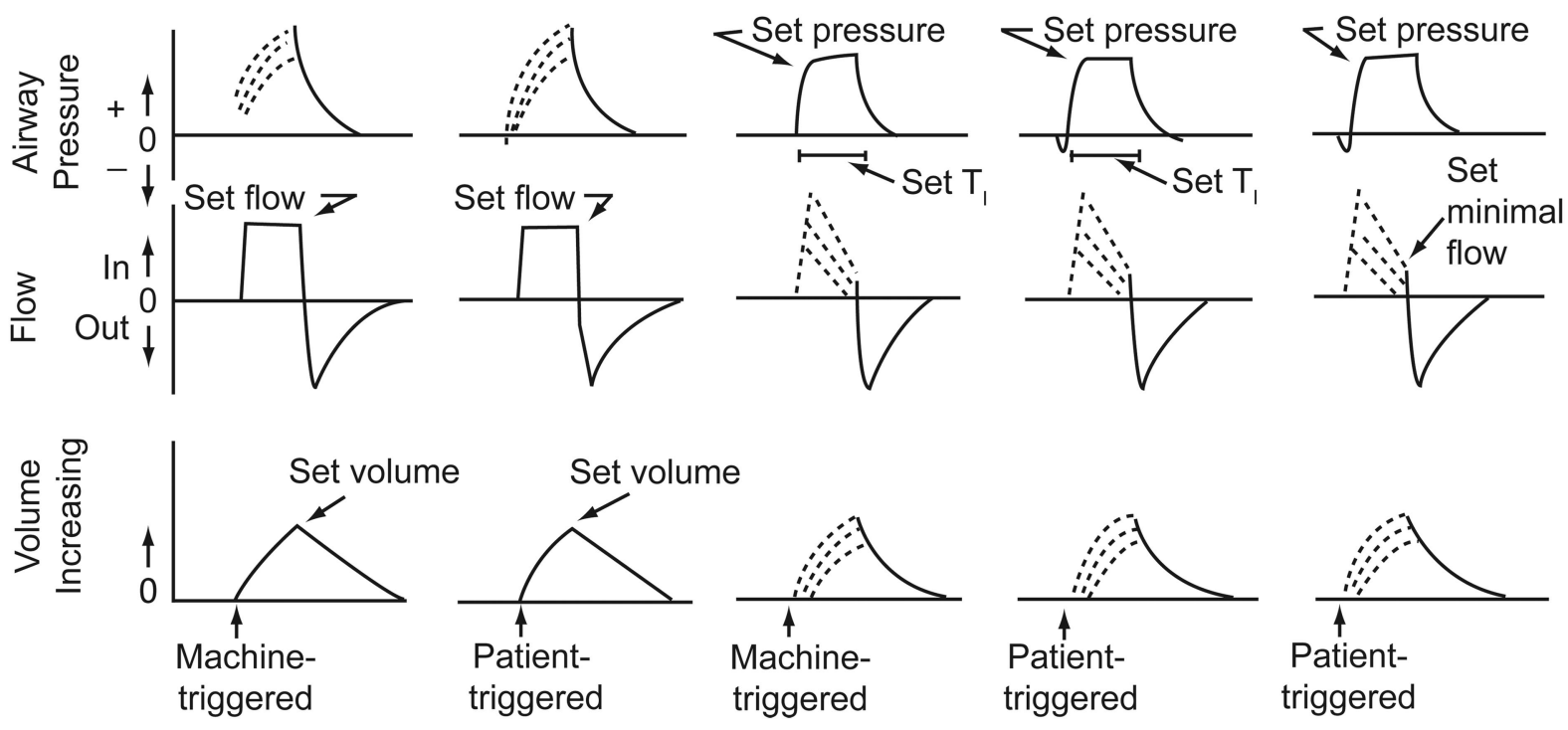

Fig. 1. Airway pressure, flow, and volume tracings illustrating the 5 basic breath types in Table 1. The solid lines indicate clinician-set parameters. The dotted lines indicate variable effects determined by respiratory-system mechanics and effort. $\mathrm{T}_{1}=$ inspiratory time. (Adapted from Reference 1, with permission.)

Table 2. Ventilation Modes and the 5 Basic Breath Types and Spontaneous Unassisted Breaths

\begin{tabular}{|c|c|c|c|c|c|c|}
\hline \multirow[b]{2}{*}{ Mode } & \multicolumn{6}{|c|}{ Breath Types Available } \\
\hline & $\begin{array}{l}\text { Volume } \\
\text { Control }\end{array}$ & $\begin{array}{l}\text { Volume } \\
\text { Assist }\end{array}$ & $\begin{array}{l}\text { Pressure } \\
\text { Control }\end{array}$ & $\begin{array}{c}\text { Pressure } \\
\text { Assist }\end{array}$ & $\begin{array}{l}\text { Pressure } \\
\text { Support }\end{array}$ & Spontaneous \\
\hline Volume assist control & + & + & & & & \\
\hline Pressure assist control & & & + & + & & \\
\hline Volume SIMV & + & + & & & + & + \\
\hline Pressure SIMV & & & + & + & + & + \\
\hline Pressure support & & & & & + & \\
\hline
\end{tabular}

nally, the distribution of various breath types in various modes (ie, the number of controlled vs assisted breaths, and the number of assisted vs supported vs spontaneous unsupported breaths) can also be clinician-selected, based on various clinical goals. How these features can be used to optimize synchrony is described in more detail below.

\section{Monitoring Techniques for Synchrony}

There are a number of ways to monitor patient-ventilator interactions on current mechanical ventilator models. ${ }^{11-15}$ Importantly, clinical observation should always be at the forefront of monitoring. This includes not only monitoring vital signs, but also assessing the patient's comfort. While comfort may be difficult to define, discomfort is characterized by anxiety, diaphoresis, nasal flaring, and just "looking miserable." A useful technique is to place one's hand on the chest to feel patient effort and then observe the ventilator's behavior, looking particularly for triggering delays, missed efforts, flow starvation, and mismatching of effort and breath cycling. Clinical monitoring also involves evaluating the patient's metabolic status (especially gas exchange and acid-base balance), and assuring that pain is adequately managed.

On the ventilator itself, understanding of the airway pressure and flow graphics is critical. ${ }^{11-13}$ Classical signs of asynchrony are airway pressure graphics that depict marked negative deflections during the triggering process, marked negative pressure during the flow delivery, and both positive and negative airway pressure graphics depict deflections during the cycling process. ${ }^{5,6,11-13}$ Indeed, when the area under the airway pressure graphic during an assisted breath is compared to a controlled breath, one can calculate the amount of patient work being done or patient 
load being borne during all 3 phases of interactive breaths. ${ }^{12}$ Esophageal and transdiaphragmatic pressure can also be used for the same purpose.

Flow graphics can also give clues to problems with patient-ventilator asynchrony. ${ }^{5,6,11-13}$ Spikes in flow or sluggish inspiratory flow often indicate that flow is not in synchrony with patient efforts. Expiratory flow is also important to evaluate. Reversals of flow during expiration may signify patient inspiratory efforts during expiration. Expiratory flow that does not return to the zero baseline before the next breath is delivered might reflect the development of intrinsic PEEP. ${ }^{11}$

\section{Using These Conventional Features at the Bedside to Improve Patient-Ventilator Interaction}

As noted above, the clinician has several tools to improve patient-ventilator synchrony. Importantly, as synchrony improves in one aspect of breath delivery (eg, triggering), patient dyspnea, and thus respiratory drive, may decrease, making other aspects of breath delivery easier to synchronize. ${ }^{16-18}$ Similarly, as asynchrony worsens in one aspect of breath delivery, dyspnea, and thus respiratory drive, may increase, making other aspects of breath delivery more difficult to synchronize. Another example is cycling asynchrony worsening air-trapping and thus triggering. Simply put: "synchrony begets synchrony, and asynchrony begets asynchrony."

\section{Optimizing Breath Triggering}

The clinician should choose the trigger sensor (flow vs pressure) that is most sensitive and responsive to patient effort. ${ }^{19}$ Importantly, some ventilators have both types of effort sensors present and will respond to whichever signal is detected first. With either sensor, the clinician should adjust the triggering sensitivity to be as sensitive as possible without causing auto-triggering. Evaluation of the airway or esophageal pressure graphic before ventilator flow hits the target value allows quantification of the triggering load on the patient. ${ }^{19}$ The more insensitive and unresponsive the trigger is, the more negative will be the pressure-time profile. Indeed, the triggering load can be quantified either as work or pressure-time product via analysis of these tracings.

If intrinsic PEEP is producing a triggering load (a problem often seen in patients with substantial air-flow obstruction), clinical observation will reveal a marked delay between the initiation of patient effort and the beginning of flow delivery, and possibly missed efforts. ${ }^{20-22}$ Graphically there may be transient reductions in expiratory flow, due to efforts that did not trigger breaths. The airway pressure graphic, however, is often unremarkable because the patient's efforts are insufficient to overcome the in- trinsic PEEP and thus are not detected in the ventilator circuit. In contrast, an esophageal pressure tracing will clearly show the elevated intrathoracic pressure from intrinsic PEEP and the ineffective patient efforts to overcome that pressure.

The first way to address this is to try reducing the intrinsic PEEP as much as possible by reducing minute ventilation (eg, reduce controlled ventilation, reduce the ventilation needs driving the patient efforts), lengthening the expiratory time, or improving the airway mechanics. ${ }^{23}$ In addition, the triggering load from intrinsic PEEP can be reduced by applying a judicious amount of circuit PEEP, which serves to narrow the difference between circuit and intrinsic PEEP. ${ }^{20-22,24,25}$ This could be guided by an esophageal pressure tracing, with the goal of providing around $70-80 \%$ of measured intrinsic PEEP as circuit PEEP. ${ }^{25}$ If an esophageal balloon is not available, an alternative approach is to empirically titrate PEEP and follow the patient's response. If the application of PEEP is benefiting the patient, the delay between effort and ventilator triggering will shorten and the patient will be observed to be more comfortable. Ironically, the breathing frequency may actually increase because more breaths that were previously missed are now being triggered. An important sign to look for is the amount of pressure required for the $\mathrm{V}_{\mathrm{T}}$. As long as the applied PEEP is less than the intrinsic PEEP, this inspiratory pressure/ $\mathrm{V}_{\mathrm{T}}$ relationship will not change. Excessive PEEP (above the intrinsic PEEP), however, will either drive up the end-inspiratory pressure (in volume-targeted ventilation) or reduce the $\mathrm{V}_{\mathrm{T}}$ (in pressuretargeted ventilation).

\section{Optimizing Flow Delivery}

Once the breath is triggered, the clinician can choose either a fixed gas flow or a variable gas flow delivery pattern, as described above. The fixed-flow breath allows the clinician control over the size of the $\mathrm{V}_{\mathrm{T}}$, but because the flow is fixed, there is generally little opportunity for the patient to alter that flow. As a consequence, a number of studies over the last 20 years have suggested that flow asynchrony is common with volume-assisted breaths. ${ }^{26-28}$ The classic clinical sign of flow asynchrony is the airway pressure graphic literally being "sucked down" during the assisted breath, as compared to the controlled breath (Fig. 2). ${ }^{26,27,29}$ If an esophageal pressure tracing is available, marked negative deflections are prominent throughout gas delivery.

There are, however, things the clinician can do to improve synchrony with a fixed-flow breath. Because the size of the $\mathrm{V}_{\mathrm{T}}$ can impact synchrony, the $\mathrm{V}_{\mathrm{T}}$ itself can be adjusted ${ }^{30}$ Indeed in the ARDS Network trial that showed the superiority of a $V_{T}$ of $6 \mathrm{~mL} / \mathrm{kg}$ versus $12 \mathrm{~mL} / \mathrm{kg}$, there was a provision to increase the $\mathrm{V}_{\mathrm{T}}$ to $8 \mathrm{~mL} / \mathrm{kg}$ (provided 


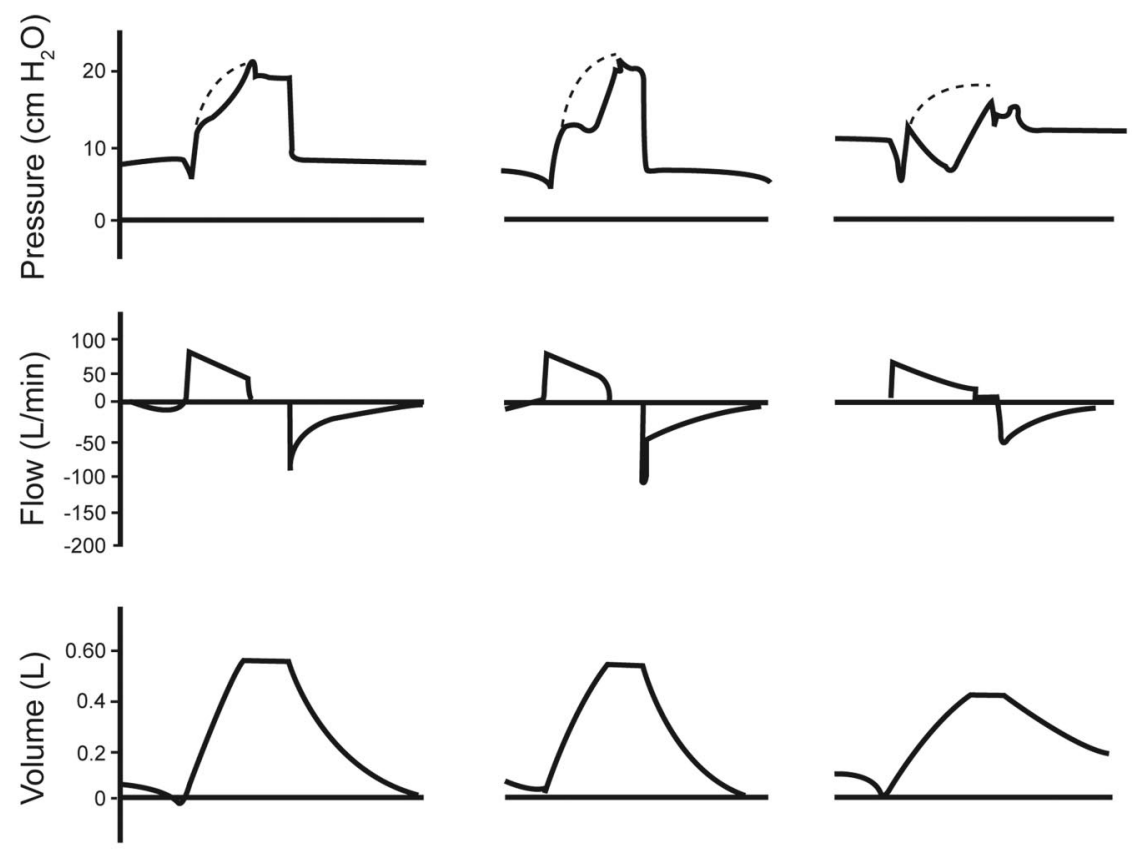

Fig. 2. Examples of 3 levels of patient-ventilator flow asynchrony seen in pressure-time, flow-time, and volume-time tracings during assisted breaths (dashed lines). The dotted pressure lines represent control breaths. In the left column the patient-ventilator flow asynchrony is mild: the assisted-breath inspiratory pressure is visibly below the control-breath inspiratory pressure, but never less than $50 \%$ of it. In the middle column the patient-ventilator flow asynchrony is moderate: the assisted-breath inspiratory pressure at some point falls below $50 \%$ of the control-breath inspiratory pressure, but never below the baseline (expiratory) pressure. In the right column the patient-ventilator flow asynchrony is severe: at some point the assisted-breath inspiratory pressure goes below the baseline (expiratory) pressure. (Adapted from Reference 29, with permission.)

the plateau pressure remained below $30 \mathrm{~cm} \mathrm{H}_{2} \mathrm{O}$ ) to improve synchrony. ${ }^{31} \mathrm{In}$ addition to $\mathrm{V}_{\mathrm{T}}$ magnitude, the magnitude and shape (sinusoidal vs square vs decelerating) of the flow can be adjusted to enhance synchrony. ${ }^{16-18,32}$ Inspiratory-time adjustments can also be made with the application of an inspiratory pause (although this may cause air-trapping in patients with airway obstruction). These manipulations are usually applied with a trial-and-error approach while constantly monitoring the airway pressure graphic and patient comfort.

An alternative to flow-targeted breaths is the pressuretargeted breath. As noted above, the pressure-targeted breath has variable flow, and this may match up better with patient effort under many circumstances (Fig. 3). The pressure-targeted breath also has several features that can enhance synchrony. One is adjustment of the rate of pressure rise to the target. ${ }^{33-36}$ This setting goes by many names, including rise time, pressure slope, and inspiratory percent, and is essentially an adjustment of the initial flow characteristics of the pressure-targeted breath and how fast the ventilator attempts to get to the pressure target. In patients with very aggressive respiratory drive, a very rapid initial flow may synchronize easier; in contrast, in patients with very weak inspiratory drive a much slower pressure rise may be needed to enhance synchrony. A way to titrate
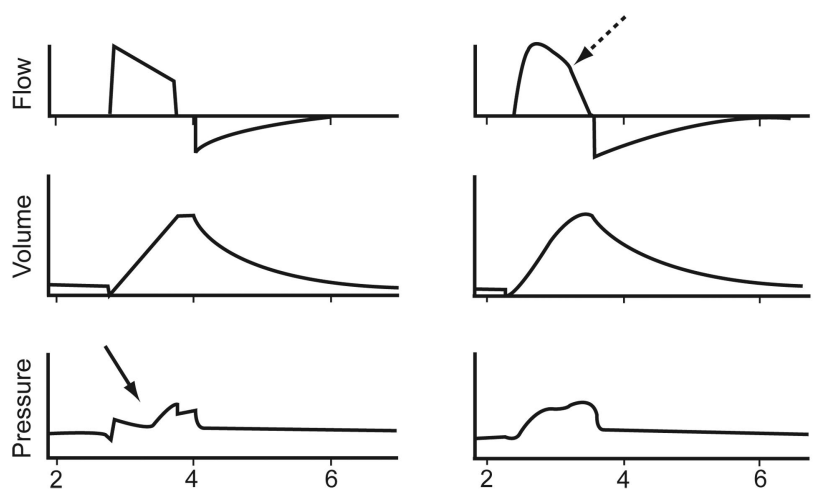

Fig. 3. Enhancing flow synchrony with a variable flow, pressure-targeted breath. In the left column, a flow-targeted breath is delivered but the flow is inadequate for patient demand and asynchrony is manifest by the deeply coved airway-pressure profile (solid arrow). In contrast, the pressure-targeted breath (right column) is set to deliver a similar $V_{T}$, but the variable flow of the pressure-targeted breath (dashed arrow) synchronizes better with patient effort, providing a smoother, more constantly positive airway pressure profile. (Adapted from Reference 29, with permission.)

this adjustment is simply to look at the airway pressure graphic and try to create a smooth square wave of pressure. ${ }^{35}$ Another approach is simply to look at the size of the $\mathrm{V}_{\mathrm{T}}$ as a marker of when the patient is synchronizing 

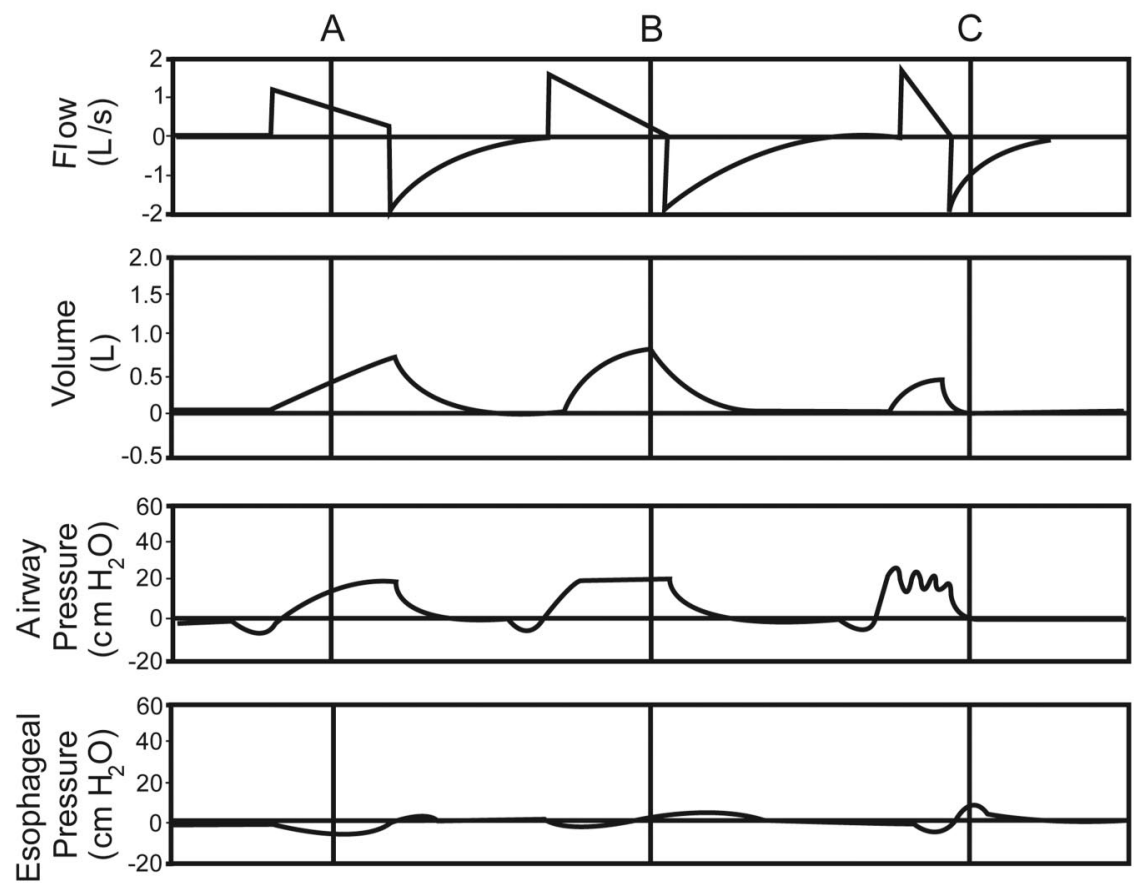

Fig. 4. Examples of different pressure rise time adjustments in 3 pressure-support breaths. In column A the rise time is set very low, so the initial flow and the rise to the pressure target are slow. In column B the rise time is set faster, so the initial flow and rise to the pressure target are faster. In column $\mathrm{C}$ the rise time is set very fast, and the airway pressure tracing shows "ringing" from what is probably excessive flow for the patient's demand. Moreover, the esophageal pressure tracing shows premature patient expiratory effort to terminate the breath. Among these 3 rise-time settings, the one in column B appears to be optimal.

with the best pressure-slope setting: the larger the $\mathrm{V}_{\mathrm{T}}$, the more the patient is probably working with the ventilator flow delivery (Fig. 4). ${ }^{35}$

Another feature of pressure-targeted breaths is the ability to compensate for the diameter of the endotracheal tube. ${ }^{37,38}$ Called by a number of proprietary names, this feature adjusts the pressure profile on the airway to create the target pressure profile at the end of the endotracheal tube. This results in a higher than set pressure target in the circuit but results in the desired square wave of pressure or more consistent CPAP application in the trachea (Fig. 5).

Importantly, the level of assistance supplied by pressure targeting will also affect synchrony in several ways. First, in the presence of air-trapping, ventilatory support reduction can reduce the air-trapping and thereby improve triggering. On the other hand, in patients without air-trapping, as the level of assistance is reduced (ie, the inspiratory pressure settings are reduced), patient respiratory drive may increase and the potential for flow asynchrony may increase ${ }^{39}$ Reducing the inspiratory pressure is often done as part of the weaning effort as the patient recovers from respiratory failure. It is important to point out, however, that evidence-based reviews of the weaning process, done over the last 20 years, have never shown an advantage from gradual reduction in support, versus simply providing stable support and doing daily spontaneous breathing trials. ${ }^{40}$ Thus, the notion of protocolized or automated reduction in inspiratory pressure in between spontaneous breathing trials must be challenged as a desirable strategy. It may be that, if one does daily spontaneous breathing trials, the level of support in between the trials is irrelevant, so aggressive pressure-reduction strategies may only increase the need for sedation from asynchrony.

A critical question is whether clinical studies support the notion that pressure targeting provides better synchrony than flow targeting. The weight of evidence suggests that indeed this is true, as most studies have shown benefit or at least comparability. ${ }^{29,41-44}$ There are times, however, when the pressure-targeting strategy may not be better. For example, at a very low pressure setting, patient assistance is minimal, so patient work may be higher than during flow-targeted breaths. ${ }^{45}$ However, this is often an intentional pressure reduction for the purpose of weaning.

There also is the risk that excessive pressure could cause central apneas during sleep. ${ }^{46,47}$ Another concern with pressure support is in obstructive-lung-disease patients, in whom the low initial flow caused by high airway resistance and a low flow-cycle criteria with pressure support results in excessively long inspiratory time and consequent air-trapping. ${ }^{48}$ Some studies have also pointed out that the benefit of pressure targeting seems to be less when the flow-targeted strategy uses a very high inspiratory flow. ${ }^{32,49}$ 
A
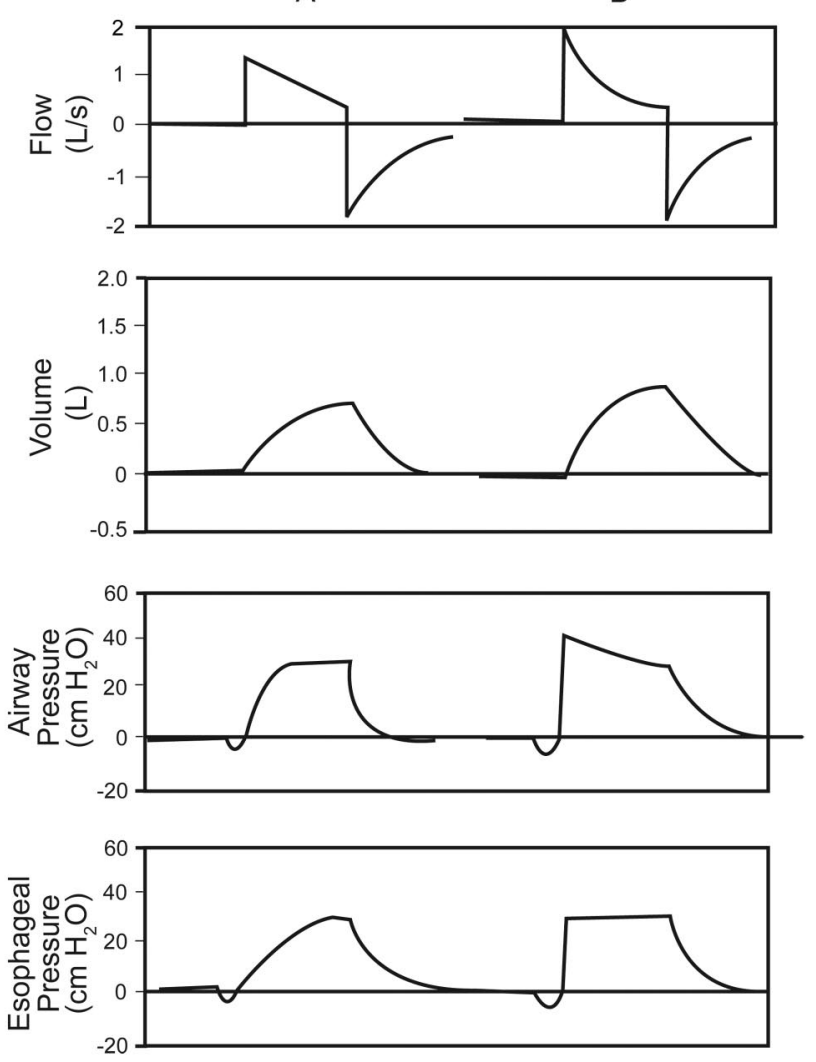

Fig. 5. Effects of an automated endotracheal-tube-compensation system on a pressure-support breath. Column A shows a typical pressure-support breath. Note that the airway (circuit) pressure curve has the desired square wave shape, but this is distorted by the endotracheal-tube resistance to a more gradually rising pressure profile in the trachea. In contrast, with an automated endotracheal-tube-compensation system (pressure support plus automatic tube compensation, column B), the airway (circuit) pressure is automatically adjusted to create the desired square wave of pressure in the trachea.

One concern about pressure targeting is that $\mathrm{V}_{\mathrm{T}}$ control is lost..$^{50}$ One way to address this is to use a feedback mode that allows the clinician to set the target $\mathrm{V}_{\mathrm{T}}$ and then automatically adjusts the ventilator's pressure-targeting algorithm. While this has theoretical appeal, it is possible that a patient with a high anxiety or pain drive to breathe may create a large $\mathrm{V}_{\mathrm{T}}$ that then results in inappropriate lowering of the inspiratory pressure. ${ }^{51}$ This is more common with a pressure-regulated volume-control mode and volume support than it is with adaptive support ventilation, in which the feedback control mechanism also includes an optimal $\mathrm{V}_{\mathrm{T}}$ and inspiratory-expiratory ratio. ${ }^{52}$

\section{Optimizing Breath Cycling}

There are several tools to improve cycling synchrony. As noted above, the size of the $\mathrm{V}_{\mathrm{T}}$ in volume-cycled ven- tilation can affect synchrony, often with larger $\mathrm{V}_{\mathrm{T}}$ satisfying the patient's respiratory drive. ${ }^{30}$ With pressure targeting the clinician has the option of using a set inspiratory time with pressure-assisted breaths, or, on most modern ventilators, of adjusting the flow-cycling criteria in pressure support. ${ }^{33}$ These features, as noted above, may be particularly important in the patient with obstructive lung disease receiving a pressure-targeted mode.

\section{The Distribution of Ventilator Breaths May Affect Synchrony}

The pattern of support may also be important in enhancing synchrony. Specifically, when more than one breath type is being delivered, the patient's respiratory controller in the brainstem is unable to predict what the next breath will be, and the potential for asynchrony may go up. In essence, the load sensed by the brainstem during one type of breath will probably alter the effort pattern response for the next breath. This has been well documented in volumetargeted SIMV, ${ }^{53}$ in which, as more and more spontaneous breaths without ventilator assistance are allowed, respiratory drive goes up, which then translates to less synchrony during the flow-targeted volume-assisted breaths. Using pressure support during these spontaneous breaths may reduce some of this effect. However, it would seem that the best clinical strategy is to provide as consistent a breath pattern as possible (ie, avoiding SIMV and supplying the fewest possible controlled backup breaths with assist-control modes). This is the most direct approach to stabilizing respiratory drive, which, conceptually, makes it easier to synchronize the ventilator and the patient.

\section{Summary}

Conventional ventilation modes have features that can monitor and enhance synchrony, including adjustment of the trigger variable, the choice of pressure-targeted versus flow-targeted breaths, and manipulation of the cycle variable. Clinicians need to know how to use these modes and monitor them properly, especially understanding airway pressure and flow graphics. Newer ventilation modes and strategies, discussed in other contributions to this Journal Conference, which involve more sophisticated flow interactive strategies and novel sensing mechanisms such as neuromuscular signals, hold promise for improving synchrony in the future, in patients with very active respiratory drive.

\section{REFERENCES}

1. MacIntyre NR. Principles of mechanical ventilation. In: Murray J, Nadel J, Mason R, Boushey H, editors. Textbook of respiratory medicine, 3rd edition. Philadelphia: WB Saunders; 2004

2. Petrof BJ, Jaber S, Matecki S. Ventilator-induced diaphragmatic dysfunction. Current Opin Crit Care 2010;16(1):19-25. 


\section{Patient-Ventilator Interactions: Optimizing Conventional Ventilation Modes}

3. Sassoon CS, Zhu E, Caiozzo VJ. Assist-control mechanical ventilation attenuates ventilator-induced diaphragmatic dysfunction. Am J Respir Crit Care Med 2004;170(6):626-632.

4. Banner MJ, Kirby RR, MacIntyre NR. Patient and ventilator work of breathing and ventilatory muscle loads at different levels of pressure support ventilation. Chest 1991;100(2):531-533.

5. Prinianakis G, Kondili E, Georgopoulos D. Patient ventilator interaction: an overview. Respir Care Clin N Am 2005;11(2):201-224.

6. Tom L, Sassoon CSH. Patient ventilator interactions. In: MacIntyre NR, Branson RD, editors. Mechanical ventilation. St. Louis: Saunders Elsevier; 2009:182-197.

7. Tobin MJ, Jubran A, Laghi F. Patient-ventilator interaction. Am J Respir Crit Care Med 2001;163(5):1059-1063.

8. Thille AW, Rodriguez P, Cabello B, Lellouche F, Brochard L. Patient-ventilator asynchrony during assisted mechanical ventilation. Intensive Care Med 2006;32(10):1515-1522.

9. Dasta JF, McLaughlin TP, Mody SH, Piech CT. Daily cost of an intensive care unit day: the contribution of mechanical ventilation. Crit Care Med 2005;33(6):1266-1271.

10. Zilberberg MD, Luippold RS, Sulsky S, Shorr AF. Prolonged acute mechanical ventilation, hospital resource utilization, and mortality in the United States. Crit Care Med 2008;36(3):724-730.

11. Unroe M, MacIntyre NR. Evolving approaches to assessing and monitoring patient ventilator interactions. Curr Opin Crit Care 2010; 16(3):261-268

12. Nilsestuen JO, Hargett KD. Using ventilator graphics to identify patient-ventilator asynchrony. Respir Care 2005;50(2):202-234.

13. Georgopoulos D, Prinianakis G, Kondili E. Bedside waveforms interpretation as a tool to identify patient-ventilator asynchronies. Intensive Care Med 2006;32(1):34-47.

14. Tobin MJ. Mechanical ventilation. N Engl J Med 1994;330(15): 1056-1061.

15. Dhand R. Ventilator graphics and respiratory mechanics in the patient with obstructive lung disease. Respir Care 2005;50(2):246-261.

16. Corne S, Gillespie D, Roberts D, Younes M. Effect of inspiratory flow rate on respiratory rate in intubated ventilated patients. Am J Respir Crit Care Med 1997;156(1):304-308.

17. Fernandez R, Mendez M, Younes M. Effect of ventilator flow rate on respiratory timing in normal humans. Am J Respir Crit Care Med 1999;159(3):710-719.

18. Manning HL, Molinary EJ, Leiter JC. Effect of inspiratory flow rate on respiratory sensation and pattern of breathing. Am J Respir Crit Care Med 1995;151(3 Pt 1):751-757.

19. Sassoon CS, Gruer SE. Characteristics of the ventilator pressure- and flow-trigger variables. Intensive Care Med 1995;21(2):159-68.

20. Chen CW, Lin WC, Hsu CH, Cheng KS, Lo CS. Detecting ineffective triggering in the expiratory phase in mechanically ventilated patients based on airway flow and pressure deflection: feasibility of using a computer algorithm. Crit Care Med 2008;36(2):455-461.

21. Milic-Emili J. Dynamic pulmonary hyperinflation and intrinsic PEEP: consequences and management in patients with chronic obstructive pulmonary disease. Recent Prog Med 1990;81(11):733-737.

22. MacIntyre NR, McConnell R, Cheng KC. Applied PEEP reduces the inspiratory load of intrinsic PEEP during pressure support. Chest 1997;111(1):188-193.

23. Marini JJ, Crooke PS 3rd. A general mathematical model for respiratory dynamics relevant to the clinical setting. Am Rev Respir Dis 1993;147(1):14-24.

24. Nava S, Bruschi C, Rubini F, Palo A, Iotti G, Braschi A. Respiratory response and inspiratory effort during pressure support ventilation in COPD patients. Int Care Med 1995;21(11):871-879.

25. Reissmann HK, Ranieri VM, Goldberg P, Gottfried SB. Continuous positive airway pressure facilitates spontaneous breathing in weaning chronic obstructive pulmonary disease patients by improving breathing pattern and gas exchange. Int Care Med 2000;26(12):17641772.

26. Marini JJ, Rodriguez RM, Lamb V. The inspiratory workload of patient-initiated mechanical ventilation. Am Rev Respir Dis 1986; 134(5):902-909.

27. Marini JJ, Capps JS, Culver BH. The inspiratory work of breathing during assisted mechanical ventilation. Chest 1985;87(5):612-618.

28. Flick GR, Bellamy PE, Simmons DH. Diaphragmatic contraction during assisted mechanical ventilation. Chest 1989;96(1):130-135.

29. Yang LY, Huang YC, MacIntyre NR. Patient-ventilator synchrony during pressure-targeted versus flow-targeted small tidal volume assisted ventilation. J Crit Care 2007;22(3):252-257.

30. Manning HL, Shea SA, Schwartzstein RM, Lansing RW, Brown R, Banzett RB. Reduced tidal volume increases 'air hunger' at fixed $\mathrm{P}_{\mathrm{CO}_{2}}$ in ventilated quadriplegics. Respir Physiol 1992;90(1):19-30.

31. The Acute Respiratory Distress Syndrome Network. Ventilation with lower tidal volumes as compared with traditional tidal volumes for acute lung injury and the acute respiratory distress syndrome. N Engl J Med 2000;342(18):1301-1308

32. Chiumello D, Pelosi P, Calvi E, Bigatello LM, Gattinoni L. Different modes of assisted ventilation in patients with acute respiratory failure. Eur Respir J 2002;20(4):925-933.

33. Chiumello D, Pelosi P, Taccone P, Slutsky A, Gattinoni L. Effect of different inspiratory rise time and cycling off criteria during pressure support ventilation in patients recovering from acute lung injury. Crit Care Med 2003;31(11):2604-2610.

34. Chiumello D, Pelosi P, Croci M, Gattinoni L. The effects of pressurization rate on breathing pattern, work of breathing, gas exchange and patient comfort in pressure support ventilation. Eur Respir J 2001;18(1):107-114.

35. Ho LI, MacIntyre NR. Pressure supported breaths: ventilatory effects of breath initiation and breath termination design characteristics. Crit Care Med 1989;17:526.

36. Bonmarchand G, Chevron V, Ménard JF, Girault C, Moritz-Berthelot F, Leroy J. Effects of pressure ramp slope values on the work of breathing during pressure support ventilation in restrictive patients. Crit Care Med 1999;27(4):715-722. Erratum in: Crit Care Med 1999; 27(7):1404

37. Fabry B, Zappe D, Guttman J, Kuhlen R, Stocker R. Breathing pattern and additional work of breathing in spontaneously breathing patients with different ventilatory demand during inspiratory pressure support and automatic tube compensation. Int Care Med 1997; 23(5):545-552.

38. Haberthür C, Mehlig A, Stover JF, Schumann S, Möller K, Priebe HJ, Guttmann J. Expiratory automatic endotracheal tube compensation reduces dynamic hyperinflation in a physical lung model. Crit Care 2009;13(1):R4.

39. Leung P, Jubran A, Tobin MJ. Comparison of assisted ventilator modes on triggering, patients' effort, and dyspnea. Am J Respir Crit Care Med 1997;155(6):1940-1948.

40. ACCP/SCCM/AARC Task Force. Evidence based guidelines for weaning and discontinuing mechanical ventilation. Chest 2001;120(6 Suppl):375S-395S.

41. Kallet RH, Campbell AR, Dicker RA, Katz JA, Mackersie RC. Effects of tidal volume on work of breathing during lung-protective ventilation in patients with acute lung injury and acute respiratory distress syndrome. Crit Care Med 2006;34(1):8-14.

42. MacIntyre NR, McConnell R, Cheng KC, Sane A. Patient-ventilator flow dyssynchrony: flow-limited versus pressure-limited breaths. Crit Care Med 1997;25(10):1671-1677.

43. Cinnella G, Conti G, Lofaso F, Lorino H, Harf A, Lemaire F, Brochard L. Effects of assisted ventilation on the work of breathing: volume- controlled versus pressure-controlled ventilation. Am J Respir Crit Care Med 1996;153(3):1025-1033. 
44. Kallet RH, Campbell AR, Alonso JA, Morabito DJ, Mackersie RC. The effects of pressure control versus volume control assisted ventilation on patient work of breathing in acute lung injury and acute respiratory distress syndrome. Respir Care 2000;45(9):1085-1096. Erratum in: Respir Care 2000;45(11):1416.

45. Kreit JW, Capper MW, Eschenbacher WL. Patient work of breathing during pressure support and volume-cycled mechanical ventilation. Am J Respir Crit Care Med 1994;149(5):1085-1091.

46. Parthasarathy S, Tobin MJ. Effect of ventilator mode on sleep quality in critically ill patients. Am J Respir Crit Care Med 2002;166(11): 1423-1429.

47. Toublanc B, Rose D, Glerant JC, Francois G, et al. Assist-control ventilation vs. low levels of pressure support ventilation on sleep quality in intubated ICU patients. Int Care Med 2007;33(7):1148-1154.

48. Jubran A, Van de Graaff WB, Tobin MJ. Variability of patientventilator interaction with pressure support ventilation in patients with chronic obstructive pulmonary disease. Am J Respir Crit Care Med 1995;152(1):129-136.
49. Kallet RH, Campbell AR, Dicker RA, Katz JA, Mackersie RC. Work of breathing during lung-protective ventilation in patients with acute lung injury and acute respiratory distress syndrome: a comparison between volume and pressure-regulated breathing modes. Respir Care 2005;50(12):1623-1631.

50. Jaber S, Delay JM, Matecki S, Sebbane M, Eledjam JJ, Brochard L. Volume-guaranteed pressure-support ventilation facing acute changes in ventilatory demand. Intensive Care Med 2005;31(9):1181-1188.

51. Jaber S, Sebbane M, Verzilli D, Matecki S, Wysocki M,. Adaptive support and pressure support ventilation behavior in response to increased ventilatory demand. Anesthesiology 2009;110(3):620-627.

52. Imsand C, Feihl F, Perret C, Fitting JW. Regulation of inspiratory neuromuscular output during synchronized intermittent mechanical ventilation. Anesthesiology 1994;80(1):13-22.

53. Marini JJ, Smith TC, Lamb VJ. External work output and force generation during synchronized intermittent mechanical ventilation. Effect of machine assistance on breathing effort Am Rev Respir Dis 1988;138(5):1169-1179.

\section{Discussion}

Epstein: Neil, you showed data from the study by Jubran ${ }^{1}$ that found that pressure support led to cycling problems in patients with COPD, but wasn't that only at fairly high levels of pressure support, above $15 \mathrm{~cm} \mathrm{H}_{2} \mathrm{O}$ ?

1. Jubran A, Van de Graaff WB, Tobin MJ. Variability of patient-ventilator interaction with pressure support ventilation in patients with chronic obstructive pulmonary disease. Am J Respir Crit Care Med 1995;152(1): 129-136.

MacIntyre: It requires a fair amount of pressure support to really magnify this issue. But you know, Scott, I still think it's important to assess any time you have someone with an obstructive disease in pressure support, just to make sure you don't run into trouble. When it happens, you get long inspiratory times and clear airtrapping, and it's just a question of being aware of it. You're right that it certainly becomes more obvious and more manifest if you're using a perhaps excessive level of pressure support.

Epstein: I'm not an advocate of it, but the cycle criteria of just $5 \mathrm{~L} / \mathrm{min}$ may not be an ideal setting.

MacIntyre: My conclusion is not to abandon pressure support in those pa- tients, but to recognize this possibility and to recognize that you have a lot of tools that you can use to fix it. Maybe a lower pressure support: certainly adjusting the cycle criterion. What I do is put the patient on pressure assist and set the inspiratory time.

Epstein: I have no particular opinion about automated weaning or the SmartCare system, but I think it is important to note that the Australian study ${ }^{1}$ came from a very different setting; I think those units had 24-houra-day attending coverage, and a much higher caregiver-to-patient ratio than in the Brochard study. ${ }^{2}$ So maybe they were not studying quite the same patient population.

1. Rose L, Presneill JJ, Johnston L, Cade JF. A randomised, controlled trial of conventional versus automated weaning from mechanical ventilation using SmartCare/PS. Intensive Care Med 2008;34(10):17881795.

2. Lellouche F, Mancebo J, Jolliet P, Roeseler J, Schortgen F, Dojat M, et al. A multicenter randomized trial of computer-driven protocolized weaning from mechanical ventilation. Am J Respir Crit Care Med 2006; 174(8):894-900.

MacIntyre: I think it's absolutely critical in looking at any clinical study (and I'm preaching to the choir here) to recognize the potential for 3 fatal flaws:
1. Picking the wrong population that either would not benefit from or would be harmed by the intervention. I think large studies that take all comers are guilty of that.

2. Picking an end point that doesn't make any sense, or trying to use a physiologic end point that may have no relationship whatsoever to outcome.

3. Failing to make sure your control group is a fair control group.

With those thoughts in mind, I'd like to address a few recently published automated weaning studies. We've had the weaning guidelines for 9 years now, and I get asked to update them from time to time, but I really have no interest in updating them because I don't think anything that new has come out. Clearly, the guidelines state that the daily SBT [spontaneous breathing trial] is the way to manage these patients, and to be aggressive about doing those. If you're going to sell me on SmartCare or another automated system, it's got to be compared to a control group that gets a daily SBT. I'm not sure you need oneto-one nursing to do that, what you need is a team who understands the daily SBT requirement and does it.

Kacmarek: I agree with everything you said, Neil. But that SmartCare trial demonstrated at least equivalence to SBTs. It showed that in the average 
ICU throughout theworld the SmartCare was a better approach because a daily SBT is not normally done in the average ICU. In my own institution, where we have harped and harped on doing daily SBTs, they are not always done every day. If a ventilation mode ensures that the patient gets weaned as quickly as with a therapist-driven protocolized SBT, that mode is pretty good to me. The study does present evidence in support of SmartCare.

MacIntyre: But the notion is that SmartCare tells you to do a daily SBT. A cheaper, simpler way to do it would be to put up a sign that reads "Do a Daily SBT."

Kacmarek: But SmartCare will do the SBT for you, so you don't have to do anything. The closed-loop controlled approach is currently available in Europe; it's not yet approved in the United States. SmartCare will decrease pressure support to the level that meets criteria for the SBT and does the SBT automatically, then puts them back on pressure support, and then tells you if the patient is ready to be discontinued from ventilatory support.

MacIntyre: I like the part about telling you and doing an automatic SBT for you. My problem is that it first must reduce (wean) the pressure support to a minimal level before it proceeds to an SBT. Remember that the 2 large weaning trials ${ }^{1,2}$ in the $1990 \mathrm{~s}$ showed that weaning often delayed conducting an SBT. My point is that I think that you may end up wasting a day or more weaning the pressure support when you could've just done an SBT that day. One of the assumptions of SmartCare is that you've got to wean the pressure support to a certain level before you can do an SBT, and I would challenge that assumption.

1. Esteban A, Frutos F, Tobin MJ, Alía I, Solsona JF, Valverdú I, et al. A comparison of four methods of weaning patients from mechanical ventilation: the Spanish Lung Fail- ure Collaborative Group. N Engl J Med 1995;332(6):345-350

2. Brochard L, Rauss A, Benito S, Conti G, Mancebo J, Rekik N, Gasparetto A, Lemaire F. Comparison of three methods of gradual withdrawal from ventilatory support during weaning from mechanical ventilation. Am J Respir Crit Care Med 1994; 150(4):896-903.

Kacmarek: Neil, I agree with you $100 \%$. Daily SBTs is the way everybody should be doing it, but it is not being done. So whether or not we believe it's the best approach, if this automated mode is equivalent to the best approach, then it's pretty good. That's what you said, and that is what the data indicate.

MacIntyre: If I could design the system, it would ask 4 basic questions:

1 . Is the respiratory status stable or improving?

2. Is gas exchange at a reasonable level? And you can define whatever reasonable level you want.

3. Are the hemodynamics stable? An easy way to do that is to ask if they're on pressors.

4. Will they take a spontaneous breath?

If they meet those 4 criteria, I think they should have an SBT. If they have a machine that will do that for me, I'll get one.

Chatburn: Wouldn't you make an exception for patients who have failed multiple SBTs and are ventilator-dependent? In those patients doesn't it look like you have to more gradually reduce the support?

MacIntyre: Rob, you're exactly right. The population you just mentioned used to be very uncommon, but it's certainly becoming more common. I had the privilege of being involved with a prolonged-mechanical-ventilation consensus group, and that group agreed with you and said that if the patient has had multiple SBT failures and you're looking at 2 or 3 weeks on the ventilator, maybe daily SBT "flogs" are not in that patient's best interest. The consensus from that group is interesting: they said that what you need to do is to find out what level of support they're on, get it to at least below $50 \%$ of that level, and then restart the SBT attempts. I agree with you: the prolonged ventilator-dependent patient is a more challenging one.

Kallet: Neil, I want to touch on something you said earlier that I think is extremely important to this conference. You talked about mixing breath types and how that might confuse the patient, and this is something that we discovered in one of our work-ofbreathing studies. ${ }^{1}$ My impression is that with dual modes such as AutoFlow and APRV [airway pressure release ventilation], if the breathing environment is constantly changing (either directly trying to adapt to the patient's demand or irrespective of it), that it can increase the work of breathing and increase central respiratory drive.

I thought back to the times when I've gotten the wind knocked out of me playing sports. You're lying on the ground gasping for air and your brain is throbbing with an incredible drive to breathe! But in that situation, you only have only one external signal to deal with: an airway opening pressure that is ambient and constant. If you're getting support from a ventilator, if that signal's constantly changing, trying to adapt to you, you may get into this feedback loop that just spins off.

What I didn't expect to find in our study was that volume control with a high flow would be better, and next best was pressure control. That's when I started to think that maybe if you hit the patient in distress with a constant volume or constant airway pressure, and a constant inspiratory time, that it gives them something to lock into. It may not apply to weaning, but when the patient is in distress, we might be getting too smart for ourselves trying to find modes that constantly adapt to 
the patient, when, ironically, the patient is trying to find something to adapt to!

1. Kallet RH, Campbell AR, Dicker RA, Katz JA, Mackersie RC. Work of breathing during lung-protective ventilation in patients with acute lung injury and acute respiratory distress syndrome: a comparison between volume and pressure-regulated breathing modes. Respir Care 2005;50(12): 1623-1631.

MacIntyre: Rich, that makes a lot of sense to me. I would point out one thing, though, about respiratory drive. I've been intrigued over the last several years by a number of papers that have pointed out that none of us has a homogenous constant tidal volume. It's natural to have some variability, and that volume variability has benefits in terms of gas distribution. Having said that, I think having a somewhat reliable delivery pattern with every breath from the ventilator does make some sense.

Branson: I agree with Bob that the promise of closed-loop weaning is consistency and preventing people going off in their different directions. I' $m$ with you. There were limitations to that study, but I think that's really where the advantage is. And if we were sitting here with the marketing managers of a company, the next question would be, "So, what would you be willing to pay for that?" I think it's $\$ 5,000$ to $\$ 6,000$ to add SmartCare to your Dräger ventilator. The question is, depending on how many ventilators you have, what's the total cost/ potential benefit of that in your particular ICU?

Kacmarek: Two days in the ICU over a year and you'd save the money. Just 2 days, not 2 patients.

MacIntyre: At our place, our education coordinator Bob Campbell routinely monitors the things that I think are important: how often do we exceed plateau pressure limits, how of- ten do we exceed the $6-\mathrm{mL} / \mathrm{kg}$ tidal volume limit, and how often do we do the daily SBTs when they're indicated? I'm the first to admit that we're not $100 \%$ on any of those parameters, but we're working on it.

Parthasarathy: If there's that variability or that issue in ivory tower universities, then it is certainly going to be an issue in community-based hospitals. This is where I think we need to move from evidence-based medicine (derived from randomized controlled trials) to translating such knowledge to the patient's bedside. There is this whole field of implementation science or cost-effectiveness medicine. These are not physiology researchers or critical care researchers: they are health-services researchers. So if someone were to do a study wherein they study implementation science in that they study the effect of SmartCare on bedside implementation of such principles in a community rather than tertiary-care hospital, then the odds are extremely good that they will show improvement and the costeffectiveness of such a system. I think that because we have the equivalence in one particular setting that doesn't mean that the SmartCare should never see the light of day again.

MacIntyre: I agree to a certain extent. I think machines that can remind us to do things like that are important. Does it have to be something that incorporates pressure-support weaning and then automatically does it, or could there be a simpler $\$ 500$ addition such as a decision-support tool on your ventilator that lights up a section of the display in fancy colors and indicates that this needs to be done, that your tidal volume's too high, that your PEEP is off the table, or that you haven't done your SBT.

Sassoon: In the graph that you showed us of volume control and pressure control, there's a concavity toward the $\mathrm{Y}$ axis on the airway-pres- sure waveform with volume control. In that case, if you just raise the flow rate, wouldn't that just take care of it, similar to pressure control?

MacIntyre: It does sometimes. We frequently put patients on volume assist and many of them do just fine; I don't want to make it sound like it's a public health hazard, that volume control is harming people.

Branson: SIMV [synchronized intermittent mandatory ventilation] is a public health hazard.

Sassoon: Have you used pressurecontrol volume-assured ventilation? In my experience that seems to be a better mode than just plain pressure control.

MacIntyre: We kind of like the pressure-regulated volume control. I'm very anxious to hear Rich's presentation tomorrow, because he's collected some interesting data on that. It does have some logic to it; it tries to stay more or less on the ARDS [acute respiratory distress syndrome] Network algorithm. There's some logic, if you want to use pressure-targeted modes, that putting that feedback mode feature into it might help you stay within your target ranges a little better. I know Rich has some data that suggest that's not always the case, and I think we'll have some fun talking about that.

Kallet: Actually, I'm speaking on APRV tomorrow.

MacIntyre: Well, I'm going to make you talk about it, and PRVC [pressureregulated volume control] as well.

\section{Kallet: OK.}

MacIntyre: Rich has shown some interesting data, and we actually see this too in the ARDS Network data. When we looked at when and where we were violating $6 \mathrm{~mL} / \mathrm{kg}$ (and all 12 sites do violate $6 \mathrm{~mL} / \mathrm{kg}$ ), it's almost 
always happening at very low levels of support in the so-called weaning phase, when they often are on pressure support and their respiratory drive has recovered, and they should probably be extubated a lot faster than we're doing it. At least in our institution, most of our tidal-volume violations are at very low levels of pressure support or pressure assist, and perhaps we need that reminder to get the tube out a little faster.

Kallet: I think the problem with dual modes like APRV is just that. The problem happens when the patient wants a higher tidal volume than the target; it'll give it to them but it thinks the compliance is improving, so it brings down the pressure.

We've all but outlawed it at San Francisco General Hospital. We had a lot of problems when we used dualmode AutoFlow as our default mode. In a 6-month period alone, I found 4 patients in overt shock on AutoFlow with a peak pressure of $12 \mathrm{~cm} \mathrm{H}_{2} \mathrm{O}$ and $\mathrm{a} \mathrm{pH}$ of around 7.15. Two of these patients were in cardiogenic shock, so it didn't exactly help their after-load!
The rule of thumb is basically that if your peak pressure on someone who's very sick is less than $20 \mathrm{~cm} \mathrm{H}_{2} \mathrm{O}$, you need to take a closer look. If your peak pressures on a dual mode are in the mid-20s to mid-30s, I don't have a problem with it at all. It's a clinician problem, the same way that asynchrony is primarily a clinician problem, in that a lot of times the clinician is not recognizing that there's a problem going on.

MacIntyre: My last comment is that we have not outlawed PRVC at Duke. 